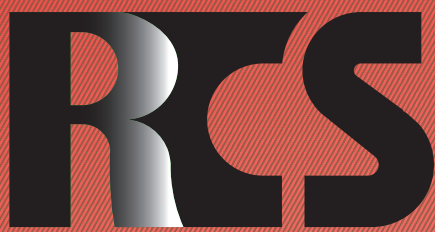

Depósito legal ppi $201502 Z U 4662$

Esta publicación científica en formato digital es continuidad de la revista impresa Depósito Legal: pp $197402 Z$ Z789

- ISSN: 1315-9518 • ISSN-E: 2477-9431

Revista de Ciencias Sociales

Universidad del Zulia. Revista de la Facultad de Ciencias Económicas y Sociales Vol. XXVII,

No. 4,2021

Esta publicación científica en formato digital es continuidad de la revista impresa Depósito Legal: pp $197402 Z 1789$ ISSN: $1315-9518$ 


\title{
Cubrimiento del posacuerdo colombiano en medios regionales en el contexto multimedial
}

\author{
Rubiano Daza, Henry* \\ Chirinos Araque, Yamarú del Valle ${ }^{* *}$
}

\section{Resumen}

El propósito del estudio es analizar el cubrimiento informativo del Posacuerdo colombiano en los medios regionales en el contexto multimedial. Metodológicamente la investigación se aborda desde el paradigma cualitativo con enfoque analítico-hermenéutico; se involucran 20 informantes clave, entre periodistas y directivos de la región, a través de Grupo Focal, mediante entrevista con preguntas abiertas para recolectar los datos; el análisis interpretativo se realizó con la ayuda del software ATLAS/ti. Los resultados indican que la prensa regional ha sido presionada por los usuarios para que reconfigure sus agendas informativas, porque expresan más interés por temas de actualidad y tendencia en redes sociales, motivo por el cual los medios presentan una escasa participación en las noticias referente al posacuerdo. Se concluye, que los medios están en la obligación de comunicar los avances de esta temática, aun cuando los usuarios estén cansados de la violencia y rechacen estas noticias al relacionar las Farc con el narcotráfico y el Gobierno Nacional con la corrupción. Ante esta situación se invita a la comunidad científica a desarrollar proyectos académicos y líneas de investigación que le expresen a la prensa regional la necesidad de agendar noticias significativas, contextualizadas, trascendentes e incluyentes como el Posacuerdo colombiano.

Palabras clave: Posacuerdo colombiano; medios regionales; noticias; contexto multimedial; Farc.

* Doctor en Ciencias Sociales y Humanas. Magíster en Historia. Comunicador Social. Periodista. Docente -Investigador de la Universidad Cooperativa de Colombia, Colombia. Premio Nacional de Periodismo Simón Bolívar 2004. Líder del Grupo de Investigación Comdehuila. E-mail: henry. rubiano@ucc.edu.co; henryrubianodaza@yahoo.com (iD) ORCID: https://orcid.org/0000-0003-3163$\underline{3014}$

** Doctora en Gestión de la Innovación. Docente-Investigadora en la Universidad Católica Luis Amigó, Medellín, Colombia. Investigadora activa de los grupos GORAS y ECOSOL. Investigadora Senior categorizada por Minciencias. E-mail: yamaru.chirinosar@amigo.edu.co; urumay78@gmail.com

(iD ORCID: https://orcid.org/0000-0003-0471-9859

Recibido: 2021-06-11 · Aceptado: 2021-08-29 


\title{
Coverage of the Colombian post-agreement in regional media in the multimedia context
}

\begin{abstract}
The purpose of the study is to analyze the news coverage of the Colombian Post-Agreement in the regional media in the multimedia context. Methodologically, the research is approached from the qualitative paradigm with an analytical-hermeneutic approach; 20 key informants were involved, including journalists and managers of the region, through a Focus Group, by means of an interview with open questions to collect data; the interpretative analysis was carried out with the help of ATLAS/ti software. The results indicate that the regional press has been pressured by users to reconfigure their news agendas, because they express more interest in current issues and trends in social networks, which is why the media show a low participation in the news regarding the Post-Agreement. It is concluded, that the media are obliged to communicate the progress of this topic, even when users are tired of violence and reject this news by linking the FARC with drug trafficking and the National Government with corruption. In view of this situation, the scientific community is invited to develop academic projects and lines of research that express to the regional press the need to schedule significant, contextualized, transcendent and inclusive news such as the Colombian Post-Agreement.
\end{abstract}

Keywords: Colombian post-agreement; regional media; news; multimedia context; FARC.

\section{Introducción}

En el contexto mundial, Colombia ha estado identificada por hechos violentos causados por las Bandas Criminales (Bacrim), y por el accionar de guerrillas como el Ejército de Liberación Nacional (ELN) y las Fuerzas Armadas Revolucionarias de Colombia (Farc); hay que recordar que esta última firmó un acuerdo con el Gobierno Nacional el pasado 24 de noviembre de 2016, luego de empezar las negociaciones en el año 2012 en La Habana.

Precisamente, sobre estos hechos violentos el Grupo de Memoria Histórica (2013), adscrito al Centro Nacional de Memoria Histórica, elaboró un informe sobre el conflicto armado en Colombia entre 1958 y
2012 (este último año considerado como el fin del accionar de este grupo guerrillero).

De acuerdo con el anterior documento, en el periodo analizado murieron 220.000 personas producto del conflicto armado, de las cuales el $81,5 \%$ corresponde a civiles y el restante $18,5 \%$ a combatientes pertenecientes a las organizaciones guerrilleras o a las Fuerzas Armadas de Colombia. Así mismo, analiza los años entre 1970 y 2010, así como reporta 27.023 secuestros asociados con el conflicto armado. De igual forma, revela que entre los años 1980 y 2012, se registraron en Colombia 1.932 masacres (ver Tabla 1). 


\section{Tabla 1}

\section{Actores y número de masacres ocurridas entre 1980 y 2012 en Colombia}

\begin{tabular}{|c|c|}
\hline Actores & Número de Masacres \\
\hline Paramilitares & 1.116 \\
\hline Guerrilleros & 343 \\
\hline Grupos Desconocidos & 295 \\
\hline Agentes del Estado & 158 \\
\hline Grupos Conjuntos entre Paramilitares y Fuerza Pública & 20 \\
\hline Total & 1.932 \\
\hline
\end{tabular}

Fuente: Grupo de Memoria Histórica, 2013.

A los anteriores datos se les suma que entre 1985 y 2012 fueron desplazadas 26 personas cada hora, mientras que fue secuestrada una persona cada 12 horas. Pero los datos no paran ahí, puesto que entre 1988 y 2012 se contabilizaron 95 atentados terroristas, con un saldo de 1.566 víctimas (Grupo de Memoria Histórica, 2013). Finalmente, el informe revela que entre 1980 y 2012 fueron asesinadas 23.161 personas de una manera selectiva, lo que demuestra la cultura violenta que se apoderó del país.

El Registro Único de Víctimas (RUV) es otro organismo que, al analizar la violencia, reporta que entre 1960 y 2012 fueron desaparecidas 25.007 personas, 1.754 individuos resultaron víctimas de violencia sexual, 6.421 niños, niñas y adolescentes fueron reclutados por grupos armados, y 4.744.046 personas fueron desplazadas (Grupo de Memoria Histórica, 2013).

Las cifras presentadas evidencian que la sociedad colombiana ha estado marcada por la violencia. Es por ello, que no se puede abandonar procesos de paz como el firmado por las Farc y el Gobierno Nacional en Colombia, que dieron origen a un Posacuerdo, el cual aún vive la sociedad colombiana.

$\mathrm{Si}$ bien es cierto que el acuerdo de paz no ha resuelto (ni resolverá) las desigualdades sociales, ni reducirá la pobreza en el territorio nacional, entre otros fenómenos sociales, lo que sí puede inferirse es que abre posibilidades para empezar a solucionarlos (Valenzuela, 2018). Es claro que los pactos permiten reducirle el camino a la agresividad y al odio, al tiempo que protegen el pluralismo de la sociedad colombiana (Oficina del Alto Comisionado para la Paz, 2016), porque donde predomina la amenaza, la exclusión y la humillación, propias de una sociedad en conflicto, habrá que esperar una mayor propensión a la violencia (Bauer, 2013).

Ahora bien, hay que precisar que el acuerdo firmado entre el Gobierno Nacional y las Farc, que generó un clima esperanzador en Colombia y permitió crear ambientes de tolerancia con el objeto de darle fin al conflicto armado y hacer posible una paz estable y duradera (Villa y Berrocal, 2019), no fue sólo voluntad de estos dos actores en mención, sino que, además, fue producto de las exigencias y presión de una sociedad colombiana que, cansada de los hechos violentos, expresó a través de los medios de información su rechazo, acompañado de movilizaciones nacionales como la del 4 de febrero de 2008, que incluso fue noticia en la prensa mundial.

Por lo anterior, los pactos y las negociaciones que conlleven a la paz son bienvenidos en cualquier escenario y se convierten en temas prioritarios de las agendas 
informativas de los medios o la prensa regional, para este caso, la colombiana.

Bajo este escenario relacionado con la violencia en Colombia, los medios masivos de comunicación no sólo han publicado la guerra de una manera directa, sino que han jugado un papel importante de control social en la búsqueda de un clima de paz que sigue incompleto, entre otras cosas porque aún tienen lugar hechos violentos a manos de las disidencias de las Farc, del ELN, y de las Bacrim (Barrios y Miller, 2020).

De ahí, la importancia de darle continuidad a la producción informativa del Posacuerdo colombiano, especialmente la publicada por la prensa regional, por su proximidad e inmediatez (López y Maciá, 2007), y porque no sólo genera opinión pública en torno a esta temática, sino que fortalece la democracia y la construcción de ciudadanía.

No obstante, y después de cerca de cinco años, en la prensa colombiana se observan cambios en la prioridad de la publicación de las noticias relacionadas con el Posacuerdo colombiano, a tal punto que ha dejado de ser información de primera plana, incluso pareciera que se lo considera como un evento ya dado, así como que la responsabilidad de la paz es exclusiva del Gobierno y de los líderes de las Farc.

Para fundamentar lo dicho anteriormente, una publicación del año 2016 del Observatorio de Medios de Comunicación Medios Para Ver (Obsemed) reveló que las noticias sobre el proceso de paz han sido poco destacadas por los medios de comunicación con mayor audiencia y lecturabilidad en el país (Reyes et al., 2016).

Precisamente, esta problemática relacionada con el aislamiento del Posacuerdo colombiano de las agendas informativas de los medios nacionales y regionales, lleva a preguntarse ¿cómo está cubriendo la prensa regional, particularmente el Diario del Huila y La Nación, el Posacuerdo colombiano?

El interrogante anterior cobra más interés si se tiene en cuenta que el tránsito de los formatos análogos a los digitales por parte de la prensa, característico de la multimedialidad, la hipertextualidad, y la convergencia, no sólo ha creado nuevas narrativas (Silverstone, 2004), sino que le ha brindado la oportunidad a sus lectores de ser escuchados y ejercer una labor informativa como prosumidores, actores propios de la "Cibercultura" o cultura de la convergencia (Jenkins, 2008), lo que ocasiona un cambio en las agendas informativas, al verse presionadas por sus nuevas audiencias.

El nuevo rol que le brindan los medios a los usuarios, producto del entorno digital, ha transformado el ejercicio periodístico, puesto que no sólo priman las relaciones sociales entre editores, periodistas y fuentes de información (Primo y Zago, 2015), sino que ha ocasionado que los lectores propongan sus propias agendas informativas.

Como consecuencia de lo anterior, la prensa regional se ha visto en la obligación de brindarles espacios a las noticias que son tendencia en las redes sociales, como deportes, farándula, y hechos insólitos, entre otras, dejando de lado temas como el Posacuerdo colombiano, que hoy, después de casi cinco años, poco es mediatizado.

En virtud de los planteamientos anteriores, se justifica la presente investigación debido a la trascendencia que tiene el tema referido a mantener espacios noticioso acerca del Posacuerdo colombiano dentro de las agendas informativas de los medios nacionales y regionales; por lo tanto, se considera relevante mencionar que para el desarrollo del estudio se formuló como propósito analizar el cubrimiento informativo del Posacuerdo colombiano en los medios regionales en el contexto multimedial, de regiones como el departamento del Huila, ubicado al sur de Colombia, que afrontó cuadros de violencia propios del conflicto interno entre las Farc, las Fuerzas Militares de Colombia y las Bacrim.

En tal sentido, la investigación se aborda desde el paradigma cualitativo bajo el enfoque analítico hermenéutico, donde se tuvo como base objeto de estudio a los periodistas y directivos de los medios "Diario del Huila" y "La Nación", el primero, fundado en agosto de 1966; y el segundo, en junio de 1994, y que cuentan con los mayores índices de 
lecturabilidad en el departamento.

\section{Nociones y entrecruzamientos del nuevo ejercicio periodístico}

El nuevo panorama que transmiten hoy los medios regionales impresos de Colombia frente al tránsito de la violencia al Posacuerdo colombiano, así como las nuevas prácticas o rutinas periodísticas, así como el diseño de agendas informativas, se prestan para ser estudiados desde categorías de análisis como la teoría del Newsmaking, la Agenda Setting, la Nueva Economía y la Convergencia Mediática.

Con relación al Newsmaking, hay que precisar que esta teoría hace referencia a la existencia de procesos dinámicos, entre los que se incluyen las rutinas informativas, que implican espacios de negociación y conflicto en torno a valoraciones periodísticas, y que los medios tradicionales no han sabido valorar en su dimensión, ni adoptar los cambios adecuados para incorporarse a la blogosfera. Es decir, que las prácticas o rutinas se transforman de un carácter normativo a un campo de realización, no rígido, que se modifica según acontecimientos imprevistos, como la relación con las fuentes de información o las demandas de públicos-objetivos, así como la infraestructura tecnológica (Arrueta, 2010).

Desde este enfoque teórico, se denota importantes avances en el estudio de las formas de producción de las noticias, que para esta investigación toma especialmente los hechos informativos que emergen del Posacuerdo colombiano, puesto que suprime las explicaciones de la noticia de una tarea compleja, así como permite herramientas útiles para analizar la relación entre la imagen y la realidad social que construyen los medios (Martini, 2000).

Como afianzamiento de este estudio, también es importante traer a colación que la Agenda Setting influye con sus noticias en el ciudadano de manera eficaz, a tal punto que atrofia al hombre y hace ver que lo que informa es lo único válido y verdadero. Sartori (2005), plantea que "cuando es así, estamos ante un público engañado y enjaulado, y por lo tanto estamos ante una opinión en el público que no es en absoluto del público" (p.85). Al tiempo que, en palabras de Cohen (1963), "la prensa no tiene mucho éxito en decir a la gente qué tiene que pensar, pero sí lo tiene en decir a sus lectores sobre qué tienen que pensar" (p.13).

Por otra parte, la Agenda Setting plantea el denominado segundo nivel o Attribute (Rodríguez, 2004; López, 2006), en el cual sugiere que el énfasis mediático de determinados atributos de los objetos sociales puede condicionar la percepción de los mismos. Dicho de otra manera, las audiencias pueden llegar a definir los objetos sociales tomando como referencia las dimensiones de las noticias que publican los medios de comunicación, que están sujetas al enfoque, a los hechos, y al tratamiento de la información, así como mediadas por los intereses de la administración del medio que tiene la decisión exclusiva de definir qué publica y qué no, mostrando "una realidad de segunda mano" (Aruguete, 2009, p.12).

De este modo, se analiza la cobertura informativa y, al mismo tiempo, la definición de los objetos sociales por parte de las audiencias (Igartua y Humanes, 2004). Al respecto, Cabrera, Lara y Ruiz (2019) sostienen que a través de los medios de comunicación "la sociedad puede acceder a cualquier clase de información pública, así como también, para acceder a opiniones que se vierten sobre los más distintos tópicos, para formar ideas propias, lo cual contribuye al debate" (p.108), puesto que, "el interés por la información y por las noticias aumenta en momentos especialmente relevantes" (Muyor y Segura, 2021, p.35).

Conforme a lo anterior, hay que decir que las agendas informativas, para este caso sobre temas del Posacuerdo colombiano, no sólo son producto del criterio de los periodistas y el actuar o interés del medio, sino que, además, intentan reflejar dinámicas de percepción de los usuarios, que bajo el uso de las Tecnologías de Información y Comunicación (TIC), transforman los productos informativos y los convierten en elaboraciones propias como 
si fueran profesionales del periodismo y/o recopiladores de noticias, para compartirlas de distintas formas, así como en diversas plataformas, convirtiéndolos en "omnimedia" (Jarvis, 2007).

Por otra parte, y muy ligado a las dos teorías anteriores, es claro que los medios están enmarcados en el crecimiento vertiginoso de las tecnologías, en donde la Nueva Economía precisa que el ecosistema y el entorno digital configuran decisivamente las formas dominantes tanto de información, comunicación y conocimiento, como de investigación, producción, organización y administración (Lévy, 2007). Sin duda las herramientas digitales han traído nuevos escenarios de debate y reflexión por los efectos de la internet, en el marco de la dinámica económica, así como la globalización, motivo sustantivo para analizar la problemática formulada en este artículo.

Así pues, la labor de construcción de las noticias, enmarcada en la rutina periodística, en especial las relacionadas con el Posacuerdo colombiano, se encuentra actualmente enfrentada a transformaciones en el contexto cibermediático (Lévy, 2007), que posibilitan repensar con mayor destreza la elaboración de productos noticiables frente a este tema. Para ser más precisos, la noticiabilidad está acordada no solo por la naturaleza de ruptura de un acontecimiento, sino por los límites de tiempo, así como espacio impuestos por el medio en el proceso de producción en el marco de la Nueva Economía y la Convergencia (Arrueta, 2010).

Ante este nuevo ecosistema digital mediático, como consecuencia de la firma del acuerdo de paz entre el Gobierno saliente de Juan Manuel Santos y los líderes de las Farc, los medios regionales se han reconfigurado, toda vez que la eclosión en las redes los ha obligado a cambiar de manera extraordinaria la producción informativa frente al tema del Posacuerdo colombiano (Carbonell, 2012).

Es claro que la internet abrió la posibilidad a los usuarios mediáticos no sólo de recibir información verticalmente, sino de dar a conocer su forma de pensar y opinar global y rápidamente como un horizontal-prosumer (Jenkins, 2008), lo que implica un nuevo perfil periodístico con prácticas polivalentes (Scolari, 2008), que domine la producción informativa para un medio caracterizado por las formas hipertextuales, la multimedialidad y la gestión de espacios colaborativos (Salaverría y García, 2008), propios de la cultura de la Convergencia, teoría que sustenta igualmente este trabajo.

\section{Metodología}

La presente investigación se aborda desde el paradigma cualitativo, bajo el enfoque analítico hermenéutico, por su interés de explorar, analizar, comprender, y describir un fenómeno, y exponer una teoría (Creswell, 2014). Para desarrollar el dispositivo metodológico del estudio, se tuvo como base objeto de estudio a los periodistas y directivos de los medios "Diario del Huila" y "La Nación", los cuales cuentan con los mayores índices de lectura en el departamento del Huila, por lo que hoy son representativos en esta zona de Colombia, según el Estudio General de Medios (EGM) (Asociación para la Investigación de Medios de Comunicación, 2019), tal como se muestra en la Tabla 2.

\section{Tabla 2}

Índice de lecturabilidad de los periódicos leídos en los últimos 30 días del EGM Tercera Ola de 2019

\begin{tabular}{lc}
\hline \multicolumn{1}{c}{ Medio } & Índice de lectura \\
\hline La Nación & 123.000 \\
Diario del Huila & 56.700 \\
El Tiempo & 37.900 \\
El Espectador & 14.800 \\
\hline
\end{tabular}

Fuente: Asociación para la Investigación de Medios de Comunicación (2019).

En la etapa de trabajo de campo, se realizó un ejercicio de muestreo intencional con 
veinte (20) personas en total; catorce (14) de ellas periodistas, que ejercían en su momento en los dos medios impresos regionales, siete (7) por cada uno de ellos; y seis (6) directivos de los mismos, tres (3) por cada medio, entre jefes de redacción, diseñadores y directores y/o gerentes.

Para la unidad de análisis, se tomó periodistas de planta en ejercicio y funcionarios de los medios regionales, que ocuparan en su momento el cargo de jefes de redacción, directores o jefes del departamento de diseño. Estos perfiles se seleccionaron con el propósito de obtener un espectro informativo más amplio que permitiera diferentes opiniones o información, con la finalidad de contribuir al análisis de cómo se está cubriendo las noticias del Posacuerdo colombiano.

Con la finalidad de recoger la información se hizo uso de tres técnicas: Análisis documental, entrevista semiestructurada, y grupo focal. Lo anterior está soportado en autores como Denzin y Lincoln (2012), quienes afirman que la investigación cualitativa es inherentemente multimetodológica, es decir, que usa distintos métodos de cara a la triangulación para reflejar y posibilitar la intención del investigador, asegurando la comprensión del fenómeno objeto de estudio.

Para analizar los relatos construidos desde entrevistas y grupos focales, se retomó la Teoría Fundamentada, dirigida a "aprender de experiencias, puntos de vista o percepciones de los individuos" (Hernández, Fernández y Baptista, 2014, p.376), y sus argumentos sobre problemáticas como las de esta investigación. Esta técnica de estudio sigue directrices analíticas que les permiten a los investigadores focalizar su recolección de datos y construir teorías a través de sucesivas recolecciones de información y desarrollos conceptuales (Charmaz, 2005). Con los 14 periodistas en ejercicio de los medios impresos regionales referenciados anteriormente, se utilizó la herramienta: Entrevista a profundidad, y a los seis directivos se les aplicó: Entrevista semiestructurada en un taller de grupo focal.

Es importante precisar que, en la etapa de reflexión, se dio lugar al desarrollo teórico que sustenta epistémica y conceptualmente la presente investigación, basado en las categorías de análisis profundizadas en el anterior apartado, a saber: El Newsmaking, la Agenda Setting, la Nueva Economía, y la Convergencia.

Se hace uso de estas categorías porque el Newsmaking, permite identificar los mecanismos de selección y valoración de los contenidos periodísticos; la Agenda Setting, ayuda a verificar la existencia de agendas informativas en los medios regionales; la Nueva Economía, abre la posibilidad de visualizar los cambios en el modelo de producción y organización de los medios como empresas en el marco de la incorporación de las TIC; y, finalmente, la Convergencia, contribuye a observar el desarrollo de la producción de información en varios formatos (Prensa, Radio, TV, entre otros), propios de la multimedialidad y el hipertexto.

En la etapa de diseño de los instrumentos, se proyectó un guion con las siguientes preguntas orientadoras, flexibles y dinámicas, entretejidas por las categorías de análisis, que cubrían todos los tópicos investigados (Taylor y Bogdan, 2000): ¿Cómo las TIC han incidido en la reestructuración y redefinición de la parte organizativa y las competencias profesionales en el periódico en el que usted labora?; ¿Han cambiado los periodistas su manera de trabajar con la incursión de las TIC?; ¿Considera usted que ha habido una reconfiguración de la agenda noticiosa (noticias a cubrir) en el medio en que usted labora, con la llegada de las TIC o es la misma de los diarios de papel?; ¿Cómo se construye la agenda informativa en el medio impreso y digital en el que usted labora?; ¿Se apoyan en las redes sociales como fuente de información para la producción de noticias?; ¿Tienen en cuenta las nuevas audiencias que emergen de sus redes sociales o páginas web para definir la agenda informativa?

Así mismo, se hizo las siguientes preguntas: ¿El medio en que usted labora maneja una agenda mediática?; ¿Qué importancia le ha dado el medio en el que labora usted al tema del Posacuerdo, después 
de la firma del acuerdo de paz entre el Gobierno Nacional y las Farc?; ¿Qué temas podrían estar por encima en el medio donde labora frente al tema del Posacuerdo, después de la firma del acuerdo de paz entre el Gobierno Nacional y las Farc?; ¿De qué fuentes reciben mayor información para redactar noticias frente al tema del Posacuerdo, después de la firma del acuerdo de paz entre el Gobierno Nacional y las Farc?

Otro bloque de preguntas fue el siguiente: ¿Se tiene en cuenta lo que exponen o comentan los usuarios de las redes sociales frente al Posacuerdo, después de la firma del acuerdo de paz entre el Gobierno Nacional y las Farc?; ¿Considera usted que ha habido una reconfiguración de la agenda mediática frente al tema del Posacuerdo, después de la firma del acuerdo de paz entre el Gobierno Nacional y las Farc? Si ha existido una reconfiguración de la agenda, ¿cuál cree usted que sea la causa de este nuevo giro?

Finalmente, y luego de la etapa de recolección de la información, se procedió a digitalizar las entrevistas y los relatos adquiridos. Posterior a ello, el proceso de análisis se realizó migrando la información a través del software ATLAS/ti, obteniendo como resultado un árbol hermenéutico que permitió discutir los resultados con mayor precisión, en contraste con los elementos teóricos o categorías de análisis vinculados al tema.

\section{Resultados y discusiones}

Para inferir los resultados del análisis de cómo ha sido el cubrimiento de la producción informativa del Posacuerdo en Colombia en la prensa regional, tomando los casos del "Diario del Huila" y "La Nación", en el contexto multimedial, se consideró necesario reflexionar sobre la incidencia del ecosistema digital en la estructura organizativa de la empresa, propia de la Nueva Economía y las rutinas periodísticas o maneras de trabajo (Newsmaking), frente al cubrimiento del Posacuerdo colombiano.

Como resultado, frente a las preguntas orientadoras en los respectivos guiones de los instrumentos, se puede interpretar que pese a la distancia de las grandes capitales, la brecha digital y la capacidad financiera, el "Diario del Huila" y "La Nación", tuvieron que hacer cambios en sus estructuras organizativas con pequeños departamentos dedicados al periodismo digital, con un community manager, un departamento de diseño, así como la vinculación de periodistas que aceptaran los retos de la modernidad digital, de lo cual se deduce que estos cambios se presentan con la finalidad de intentar dar respuesta a las exigencias de los usuarios o lectores en el entorno digital, con temas que generaran interés, como el Posacuerdo colombiano.

Así mismo, se infiere que anteriormente la prensa regional, a través de sus periodistas, manejaba una agenda informativa mucho más estable, pero que hoy está marcada por la inmediatez que se vive en las redes sociales, por ello existe información publicada acompañada de la frase final "noticia en desarrollo", como lo revelan los informantes consultados, cuyas respuestas llevan a concebir que la prensa regional debe contar con periodistas polivalentes o multitareas, necesarios para el periodismo digital, así como para mantener informada a una audiencia en temas como el Posacuerdo colombiano (ver Figura I). 


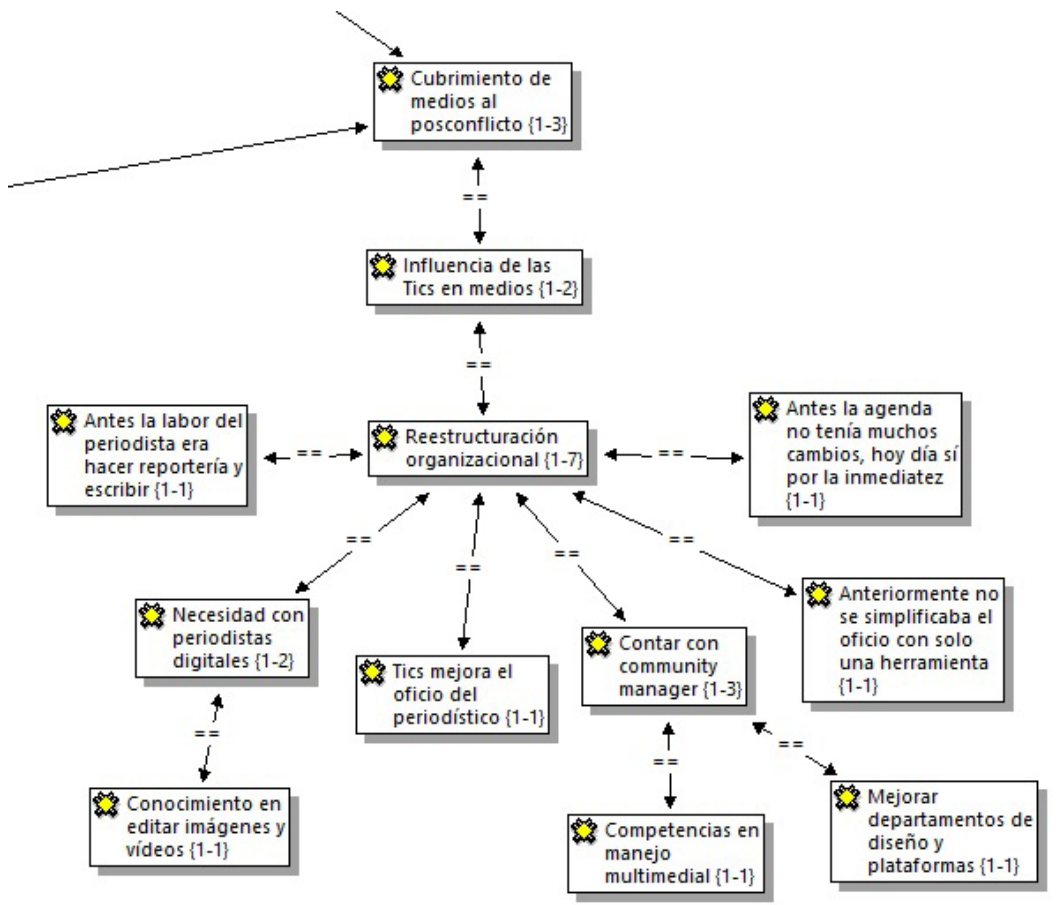

Fuente: Elaboración propia, 2021.

\section{Figura I: Árbol hermenéutico de entrevistas a periodistas sobre la influencia de las TIC en el medio}

Con relación a la Convergencia, de los resultados de la entrevista se deduce que la prensa regional intentó adaptarse a las exigencias del ecosistema digital con la creación de nuevos formatos; por ejemplo, "La Nación”, además de su impreso y su plataforma digital www.lanacion.com.co, fundó un canal de televisión (La Nación TV); por su parte, el "Diario del Huila", junto a su impreso, diseñó la página web www.diariodelhuila.com, y en ella instauró un formato de radio digital (DH Radio). No obstante, "estas estrategias no mejoraron sus audiencias, lo que los obligó a centrar la producción informativa en sus páginas web y el formato análogo", como lo expresan reiteradamente los periodistas entrevistados, desaprovechando las bondades de las tecnologías digitales y la Convergencia $y$, por ende, el desarrollo de informaciones de interés como el Posacuerdo colombiano.

Como complemento a lo anterior, se coligió desde la categoría de la Convergencia, que ante el tráfico de información en las diferentes redes sociales, sus lectores $\mathrm{y} / \mathrm{o}$ audiencias están dispuestos a trasladarse a otros portales, buscando su satisfacción informativa; por esta razón, la prensa regional le ha dado importancia a las noticias que son tendencia y a los comentarios, los like o los dislike, limitando la publicación de las noticias como el Posacuerdo colombiano que no tienen un alto grado de prioridad por parte de los usuarios (ver Figura II). 


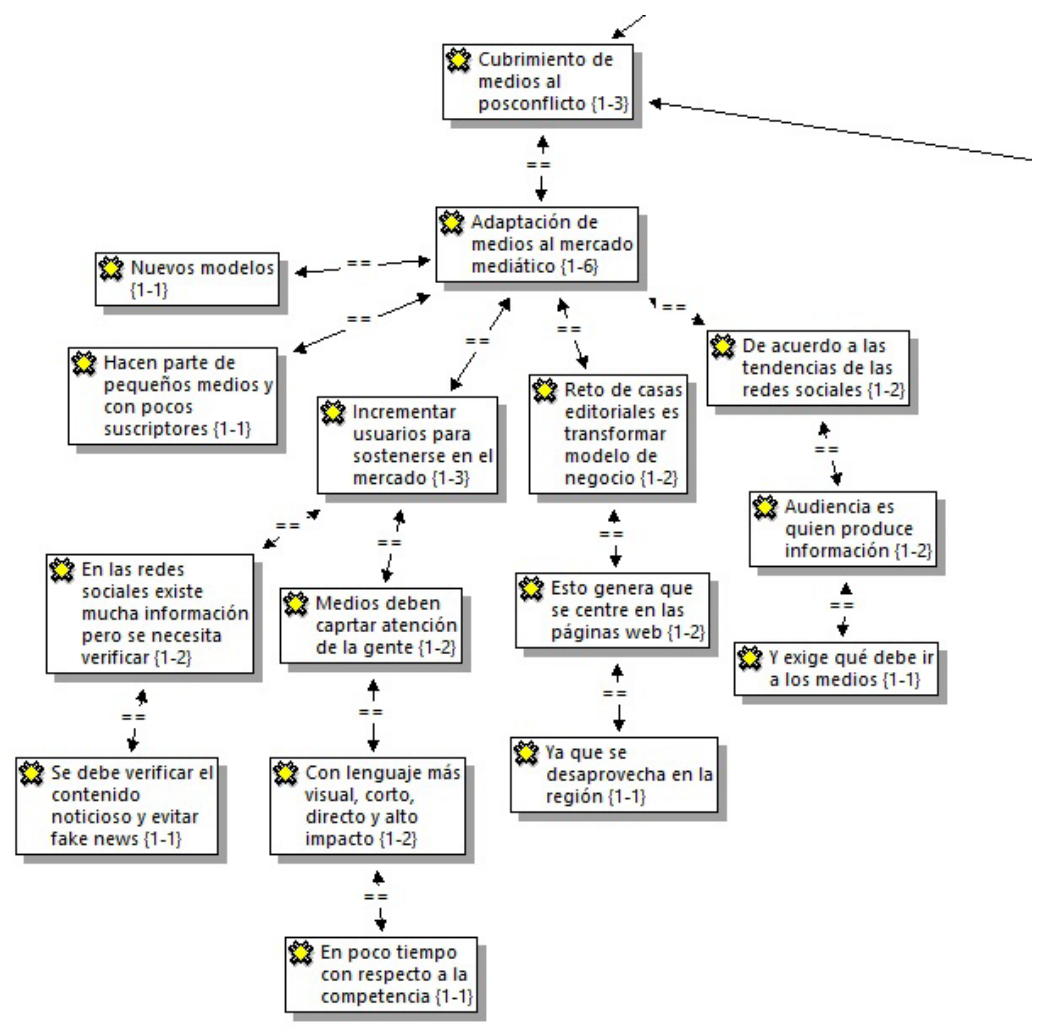

\section{Figura II: Árbol hermenéutico de entrevistas a periodistas sobre la adaptación del medio al mercado mediático}

Con relación al cubrimiento informativo del Posacuerdo colombiano, en el marco de la categoría de la Agenda Setting, se analizó que, pese a que los actores y productores de los medios tienen claro que la paz es necesaria, el flujo de información que circula en las redes está atado a las noticias tendencia, tales como hechos violentos, pasionales, de corrupción, deportivos y "rumba-cultural"; por lo tanto, el Posacuerdo pasa a un segundo plano. Por consiguiente, es relevante destacar que, luego de 50 años de historia violenta en Colombia, las noticias del Posacuerdo colombiano, deberían ser de primera página; no obstante, se enfatiza en que los actores del proceso de paz, en este caso el Gobierno Nacional y las Farc, han perdido credibilidad y, por tanto, los titulares están determinados por el interés de los usuarios reflejados en las redes sociales, más no por la naturaleza editorial de los medios.

Ahora bien, la horizontalidad que han generado las redes sociales ocasionó una reconfiguración de la agenda mediática, toda vez que hoy está marcada por las noticias tendencia. Dicho de otra manera, las agendas del "Diario del Huila" y del diario "La Nación", están enfocadas en darle gusto al usuario expuesto en las redes (ver Figura III). 


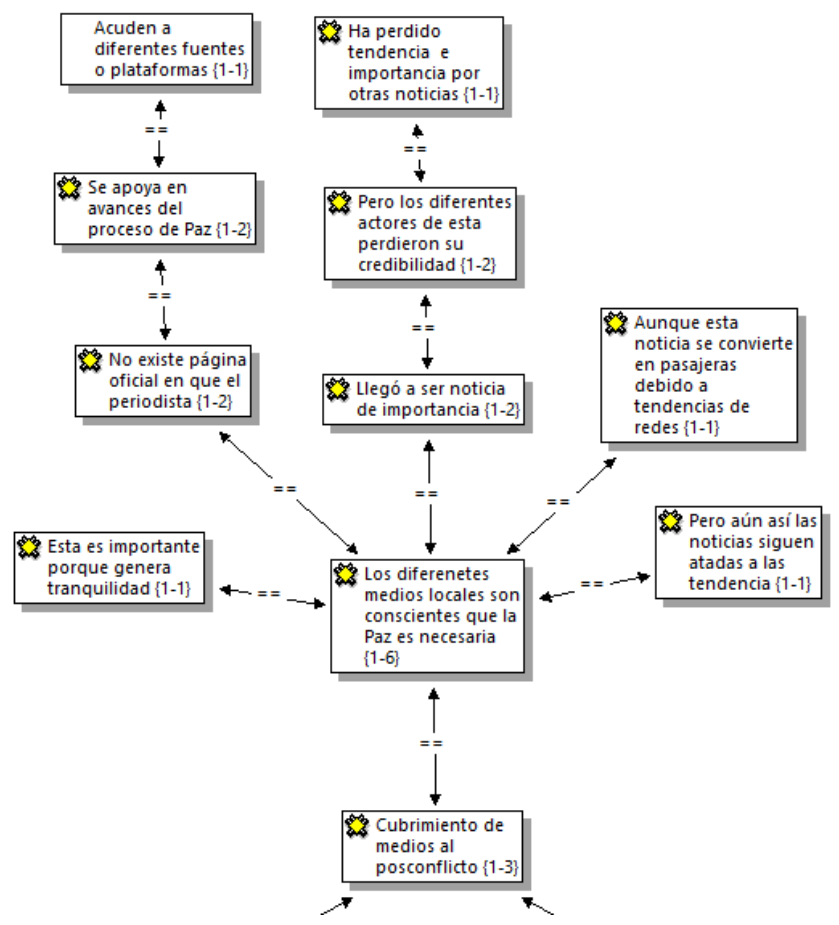

Figura III: Árbol hermenéutico de entrevistas a periodistas en relación con el cubrimiento de noticias sobre el posconflicto

Sin duda, de los resultados se infiere como análisis para la discusión, que el tema del Posacuerdo colombiano ha sido marginado en parte por la prensa regional, porque para ella, según sus audiencias, "las Farc y el Gobierno Nacional, en regiones como el Huila, han perdido credibilidad por ser protagonistas de noticias como el narcotráfico y la corrupción, situación que conlleva a que los medios les den importancia a otras noticias", según se pudo colegir de las respuestas dadas por la población entrevistada.

Es claro que la Agenda Setting toma relevancia cuando existe mayor nivel de incertidumbre sobre asuntos públicos, como el Posacuerdo colombiano, toda vez que ésta se constituye en un mecanismo para expresar la voz de aquellos que no la tienen. Por lo anterior, la prensa regional debe llenar ese vacío y moldear la conducta, así como el comportamiento de los ciudadanos (Botero, 2011), frente a temas como el Posacuerdo colombiano.

Ahora bien, los resultados igualmente llevan a debatir que, si bien es cierto que los usuarios de la prensa regional acuden a las redes sociales buscando temas distintos al conflicto armado, por estar cansados de la violencia, los medios están en la obligación de mantenerlos informados sobre el proceso de paz, más 
aún si se tiene en cuenta que el Posacuerdo colombiano no ha sido sistematizado y no existe una página web oficial de los avances obtenidos en los últimos años.

\section{Conclusiones}

Una vez realizado el análisis interpretativo de los resultados de la investigación se concluye que es importante mantener a la sociedad informada acerca de los acontecimientos en torno al Posacuerdo y la paz en Colombia. Indiscutiblemente, dichos procesos no han resuelto las desigualdades sociales, ni reducirán la pobreza en el territorio nacional, entre otros fenómenos sociales; lo evidente es que, a través de los medios de información se vislumbran oportunidades de acciones gubernamentales y de organizaciones nacionales e internacionales que posibilitan acciones para mitigar estos fenómenos.

De allí que la prensa regional, para este caso el "Diario del Huila" y el diario "La Nación", han limitado su autonomía en la definición de sus agendas informativas, ante el afán de liderar las tendencias en las redes sociales, por lo cual, emerge la publicación de las noticias que están ligadas a lo que se impone en las redes sociales, donde sus componentes de proximidad, contexto e inmediatez, están sujetos a los usuarios que como prosumidores los han obligado a reconfigurar su Agenda Setting.

Se considera que esta situación es ocasionada por que los usuarios están cansados de la violencia, además de reflejar que las noticias relacionadas con el Posacuerdo no son de su interés puesto que las Farc y el Gobierno Nacional, en regiones como el Huila, han perdido credibilidad por ser protagonistas de noticias como el narcotráfico y la corrupción, situación que conlleva a que los medios les den importancia a otras noticias que son tendencia.

Por lo anterior, es necesario insistir e invitar a los medios de comunicación a continuar informando acerca de este tema de manera veraz y objetiva; asimismo, se convoca a la comunidad científica a desarrollar proyectos académicos, así como a formular líneas de investigación que expresen la necesidad que la prensa regional, entre su política editorial, diseñe agendas significativas, contextualizadas, trascendentes e incluyentes en torno a temas como el Posacuerdo colombiano, y no solo se conforme con condicionar su producción noticiosa para satisfacer la necesidad de sus usuarios, quienes a veces navegan sin norte en las redes sociales, alejándose de su proximidad.

\section{Referencias bibliográficas}

Arrueta, C. (2010). ¿Qué realidad construyen los diarios? Una mirada desde el periodismo en contexto de periferia. La Crujía.

Aruguete, N. (2009). Estableciendo la agenda. Los orígenes y la evolución de la teoría de la Agenda Setting. Ecos de la Comunicación, 2(2). https://repositorio.uca.edu.ar/ $\underline{\text { handle/123456789/7119 }}$

Asociación para la Investigación de Medios de Comunicación (2019). Entrega de resultados EGM $3^{a}$ ola 2019. https:// www.aimc.es/blog/entrega-resultadosegm-3a-ola-2019/

Barrios, M. M., y Miller, T. (2020). Voces de resiliencia: Periodistas colombianos y autocensura en el período posconflicto. Journalism Practice. https://doi.org/1 $\underline{0.1080 / 17512786.2020 .1778506}$

Bauer, J. (2013). La violencia cotidiana y global: Una reflexión sobre sus causas. Plataforma Editorial.

Botero, L. H. (2011). Teoría de públicos: Lo público y lo privado en la perspectiva de la comunicación. Editorial Universidad de Medellín.

Cabrera, J. P., Lara, A., y Ruiz, K. M. (2019). Vulneración a la libertad de expresión: Caso los jinetes del apocalipsis. 
Rubiano Daza, Henry y Yamarú del Valle Chirinos Araque

Cubrimiento del posacuerdo colombiano en medios regionales en el contexto multimedial

Revista de Ciencias Sociales (Ve), XXV(1), 102-110.

Carbonell, J. M. (2012). El futuro de la comunicación: Redes, medios y poder. Editorial UOC.

Charmaz, K. (2005). Grounded theory in the 21st Century: A qualitative method for advancing social justice research. In N. K. Denzin y Y. S. Lincoln (Eds.), The SAGE handbook of qualitative research (pp. 507-535). SAGE Publishing.

Cohen, B. C. (1963). The press and foreign policy. Princeton University Press.

Creswell, J. W. (2014). Research design: Qualitative, quantitative, and mixed methods approaches. SAGE Publications, Inc.

Denzin, N. K., y Lincoln, Y. S. (Comps.) (2012). El campo de la investigación cualitativa: Manual de investigación cualitativa. Vol. I. Editorial Gedisa.

Grupo de Memoria Histórica (2013). ¡Basta ya! Colombia: Memorias de guerra y dignidad. Imprenta Nacional. http:// www.centrodememoriahistorica.gov. co/descargas/informes2013/bastaYa/ basta-ya-colombia-memorias-deguerra-y-dignidad-2016.pdf

Hernández, R., Fernández, C., y Baptista, M. D. P. (2014). Metodología de la investigación. McGraw-Hill/ Interamericana Editores.

Igartua, J. J., y Humanes, M. L. (2004). Imágenes de Latinoamérica en la prensa española. Una aproximación empírica desde la Teoría del Encuadre. Comunicación y Sociedad, XVII(1), 47-75.

Jarvis, J. (2007). Los periódicos en 2020. Cuadernos de Periodistas: Revista de la Asociación de la Prensa de Madrid, (12), 51-57.

Jenkins, H. (2008). Convergence culture:
La cultura de la convergencia de los medios de comunicación. Ediciones Paidós Ibérica.

Lévy, P. (2007). Cibercultura. La cultura de la sociedad digital. Anthropos.

López, G. (2006). Comunicación digital y líneas de fractura en el paradigma de la agenda setting. Doxa Comunicación. Revista Interdisciplinar de Estudios de Comunicación y Ciencias Sociales, (4), 37-58.

López, X., y Maciá, J. (2007). Periodismo de proximidad. Editorial Síntesis.

Martini, S. (2000). Periodismo, noticia y noticiabilidad. Editorial Norma.

Muyor, J., y Segura, A. J. (2021). COVID-19 y comunidad gitana: Enfoques en la prensa española. Revista de Ciencias Sociales (Ve), XXVII(1), 34-52. https:// doi.org/10.31876/rcs.v27i1.35294

Observatorio de Medios de Comunicación Medios Para Ver - Obsemed (2016). Medios de comunicación: Elecciones regionales y proceso de paz. Universidad Nacional de Colombia. https:/www.uneditorial.com/pageflip/ acceso-abierto/pdf/medios-decomunicacion-elecciones.pdf

Oficina del Alto Comisionado para la Paz (2016). El Acuerdo Final de paz: La oportunidad para construir paz. https://www.refworld.org.es/ pdfid/5a874f254.pdf

Primo, A., y Zago, G. (2015). ¿Quién y qué periodismo? Digital Journalism, 3(1), 38-52. https://doi.org/10.1080/216708 $\underline{11.2014 .927987}$

Reyes, Y., Vergara, I., Torres, O., DíazLagos, M., y González-Jimenez, E. E. (2016). Contaminación por metales pesados: Implicaciones en salud, ambiente y seguridad alimentaria. Ingeniería, Investigación y Desarrollo, 16(2), 66-77. https:// 
doi.org/10.19053/1900771X.v16. $\underline{\mathrm{n} 2.2016 .5447}$

Rodríguez, R. (2004). Teoría de la AgendaSetting: Aplicación a la enseñanza universitaria. Observatorio Europeo de Tendencias Sociales.

Salaverría, R., y García, J. A. (2008). La convergencia tecnológica en los medios de comunicación: Retos para el periodismo. Trípodos. Blanquerna School of Communication and International Relations-URL, (23), 3147. https://www.raco.cat/index.php/ Tripodos/article/view/118910

Sartori, G. (2005). Elementos de teoría política. Alianza Editorial.

Scolari, C. (2008). Hipermediaciones: Elementos para una teoría de la comunicación digital interactiva.
Editorial Gedisa.

Silverstone, R. (2004). ¿Por qué estudiar los medios? Amorrortu Editores.

Taylor, S. J., y Bogdan, R. (2000). Introducción a los métodos cualitativos de investigación: La búsqueda de significados. Editorial Paidós.

Valenzuela, P. (2018). The end of the armed conflict in Colombia: A multiple causal factor explanation. Peace \& Change, 43(2), 205-217. https://doi. org $/ 10.1111 /$ pech.12286

Villa, S. I., y Berrocal, J. C. (2019). Aportes de la democracia deliberativa en el contexto del postconflicto colombiano. Revista de Ciencias Sociales (Ve), $X X V(\mathrm{E}-1), \quad 253-263 . \quad$ https://doi. org/10.31876/rcs.v25i1.29613 